\title{
Sleep Duration in Relation to Cognitive Function among Older Adults: A Systematic Review of Observational Studies
}

\author{
Elizabeth E. Devore Francine Grodstein Eva S. Schernhammer \\ Channing Division of Network Medicine, Brigham and Women's Hospital, Harvard Medical School, \\ Boston, Mass., USA
}

\section{Key Words}

Sleep duration · Cognition · Older adults · Epidemiology

\begin{abstract}
Context: Increasing evidence suggests that circadian and sleep parameters influence cognitive function with aging. Objective: To evaluate observational studies of sleep duration and cognition in older adults. Data Sources: A systematic review of OVID Medline and PsycINFO through September 2015, and review of bibliographies from studies identified. Study Selection: English-language articles reporting observational studies of sleep duration and cognitive function in older populations. Data Extraction: Data extraction by 2 authors using predefined categories of desired information. Results: Thirty-two studies met our inclusion criteria, with nearly two-thirds published in the past 4 years. One-third of studies indicated that extreme sleep durations were associated with worse cognition in older adults. More studies favored an association with long vs. short sleep durations ( 35 vs. $26 \%$ of studies, respectively). Four studies found that greater changes in sleep duration over time were related to lower cognition. Study design and analytic methods were very heterogeneous across studies; therefore, metaanalysis was not undertaken. Limitations: We reviewed English-language manuscripts only, with a qualitative summary
\end{abstract}

C 2016 S. Karger AG, Basel

0251-5350/16/0461-0057\$39.50/0 of studies identified. Conclusions and Implications of Key Findings: Observational studies of sleep duration and cognitive function in older adults have produced mixed results, with more studies suggesting that long (rather than short) sleep durations are related to worse cognition. Studies more consistently indicate that greater changes in sleep duration are associated with poor cognition. Future studies should be prospectively designed, with objective sleep assessment and longer follow-up periods; intervention studies are also needed to identify strategies for promoting cognitive health with aging.

(c) 2016 S. Karger AG, Basel

\section{Introduction}

Accumulating evidence suggests that circadian disruption influences long-term health, as epidemiologic studies have identified associations of rotating night-shift work and extreme sleeping patterns with greater risks of type 2 diabetes, cardiovascular disease, stroke, and mortality [1-10]. In turn, diabetes and vascular disease have been linked to cognitive decline and dementia in older adults [11], suggesting that circadian disruption might influence cognitive health in later life. Small studies of emergency-room physicians and airline crews have dem-

\section{KARGER}

E-Mail karger@karger.com

www.karger.com/ned
Elizabeth E. Devore

181 Longwood Avenue, Room 448

Boston, MA 02115 (USA)

E-Mail nheed@channing.harvard.edu 
onstrated that circadian disruption and related sleep problems can lead to short-term decrements in cognitive function [12-14]; however, it remains unclear whether these exposures are detrimental for the general population or whether they influence longer-term cognition. In older adults, initial studies suggest that aberrant circadian rhythms may be related to poorer cognition [15-18] and bright-light therapy may improve cognitive impairment in Alzheimer's disease [19], further supporting a link between circadian disruption and later-life cognitive impairment.

Moreover, experimental studies have identified links between sleep disturbances and beta-amyloid dynamics in the brain [20-23], and epidemiologic studies have observed associations between various sleep characteristics and cognitive function in older adults [24]. However, complexity exists in studying these associations because it is known that Alzheimer's disease causes circadian and sleep disturbances; thus, a bi-directional association may exist between sleeping patterns and cognitive function in older adults with underlying Alzheimer's disease [22]. Despite this challenge, a growing number of epidemiologic studies have examined sleep duration (an indicator of circadian rhythm) in relation to cognition in older individuals - an association that, to date, is poorly understood.

In this review, we aimed at systematically evaluating observational studies of sleep duration and cognitive function in older adults.

\section{Methods}

Using PRISMA guidelines, we conducted a systematic review of manuscripts indexed by Medline, Ovid MEDLINE(R), and PsycINFO through September 2015 [25]. Our search string was: (sleep* and (cogniti* or memory) and (elderly OR older OR geriatric OR aging OR ageing)), where the asterisk indicates that any ending may follow the beginning of the specified term. We used this search string at the beginning of a 4 -phase process (identification, screening, eligibility, and inclusion) that determined manuscripts to be included in this review. The bibliographies of included manuscripts were also reviewed for additional studies of interest.

We were interested in identifying observational studies that reported the association between sleep duration and cognitive function, which were published in English, and focused on (or included) adults aged $\geq 65$ years. When multiple studies were published based on the same study population, we included the study that used a prospective design, or was published most recently if all studies were cross sectional. Two authors (E.E.D. and E.S.S.) performed the literature search, reviewed search results, and extracted data from identified manuscripts based on prespecified categories of information. Inconsistencies in data extraction were reconciled by discussion between these 2 authors.

\section{Results}

\section{Previous Epidemiologic Studies Identified in Our}

Search

Figure 1 is a flowchart describing the algorithm used to select studies for this review. We initially identified 4,355 records using our search criteria, and 2,423 of these were unique records that remained after removal of duplicates (Identification Phase). These articles were screened based on title and abstract, at which point 2,366 articles were excluded based on the following criteria: 225 articles were not written in English, and 2,141 articles did not evaluate the association of interest (Screening Phase). This left us with 55 full-text articles to evaluate for eligibility, of which 18 studies examined sleep characteristics other than sleep duration in relation to cognitive function [26-43], and 6 studies were based on duplicate study populations [44-49]; there were 31 remaining studies that were eligible for inclusion (Eligibility Phase). One additional study was identified based on a review of the bibliographies from these manuscripts [50]; thus, in total, 32 studies were included in our review [16, 50-80] (Inclusion Phase).

\section{Description of Studies Included in Our Review \\ Overall Study Design}

In table 1, we present the key aspects of the overall study design for each of the studies on sleep duration and cognitive function. These studies ranged in size from 26 to 32,142 participants, and were conducted across multiple countries: United States [53, 55-57, 67, 70, 72, 73, 75, 79], United Kingdom [61, 64, 77], Spain $[58,69]$, Finland [50, 68], France [54, 62], Japan [65, 78], Australia [52], Germany [59], Ireland [16], Netherlands [80], Hong Kong [66], Canada [63], Korea [60], China [76], Singapore [71]. There was also a multi-country study incorporating data from China, Ghana, India, South Africa, Russia, and Mexico [74]; the location of one study was unknown [51]. Twenty-five studies used a cross sectional design $[16,50-62,65-68,70,72,74$, $77-80]$ and 5 used a prospective design $[63,69,71,75$, $76]$, with 2 additional studies including both cross-sectional and prospective analyses [64, 73]. Thus, there were a total of 27 cross-sectional analyses and 7 prospective analyses conducted across all studies in this review. We defined cross-sectional studies as those that collected information on sleep duration and cognitive function at one point in time (generally at the same time). Prospective studies were those that collected sleep information as well as multiple assessments of cognitive func- 
Fig. 1. Flowchart of algorithm used to de-

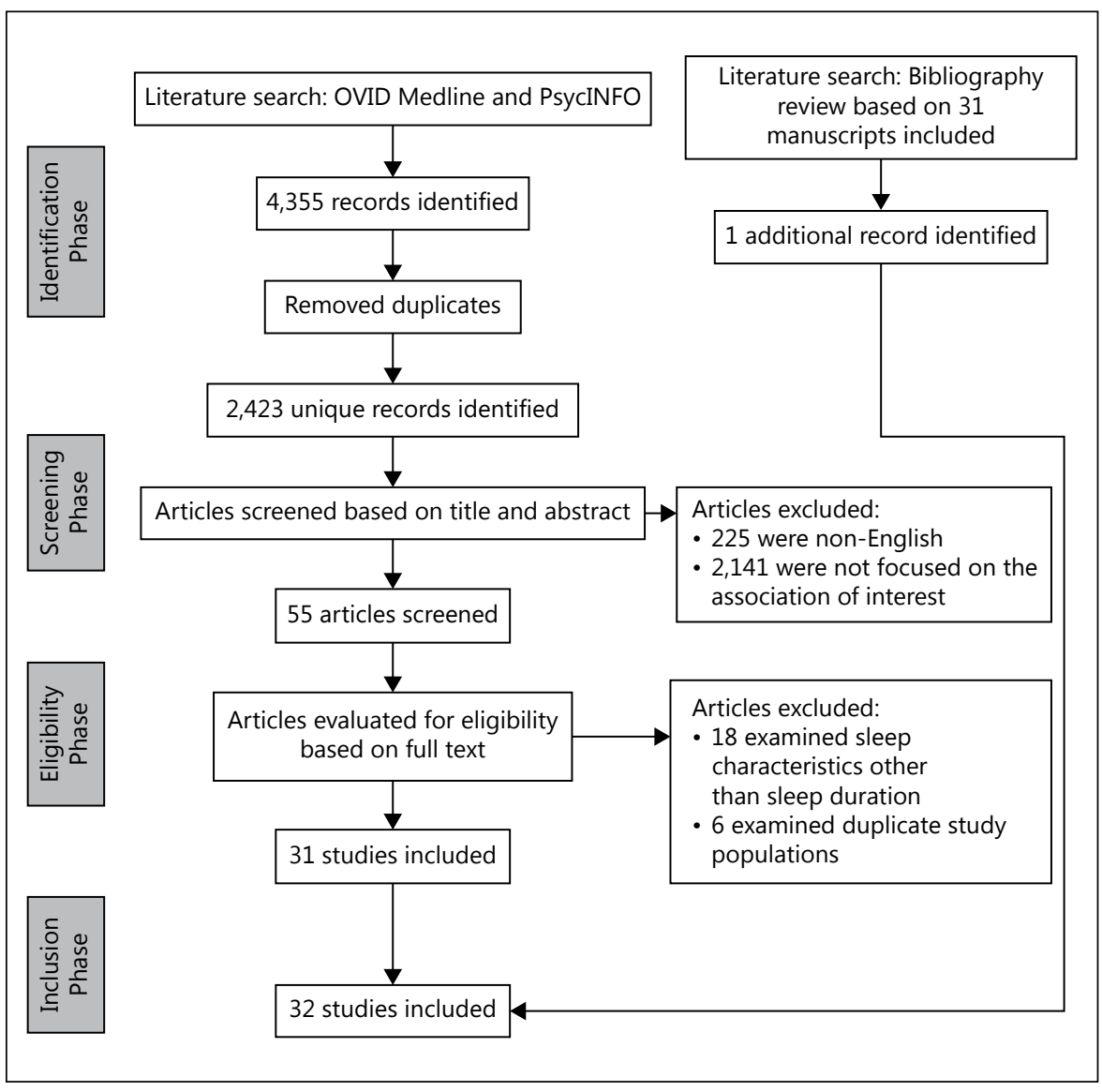
termine studies included in this review.

tion; hence, they could evaluate sleep duration in relation to change in cognitive function over time. Prospective studies had variable follow-up periods, ranging from 1 to 10 years.

\section{Study Population}

In table 1, we also describe the study population for each of the studies. Most studies included both women and men $[16,50,51,54,56-69,71,72,74,76-80]$, although some studies focused on women only $[55,70,73]$ or men only [53,75]; 1 study did not specify the sex of participants [52]. Studies generally specified age thresholds for participants at the time of first cognitive interview: $\geq 30$ years $[50], \geq 45$ years $[80], \geq 50$ years $[74,76,77]$, $\geq 55$ years [16], $\geq 59$ years [71], $\geq 60$ years $[54,58,60,65]$, $\geq 65$ years $[55,62-64,66,68,69,75], \geq 68$ years [70], and $\geq 70$ years $[59,73,79]$. Other studies provided the mean age [67] or age ranges [51-53, 56, 57, 61, 72, 78] of their participants, but did not explicitly describe an age threshold as part of the inclusion criteria; regardless, older adults were eligible for all studies. The most common ex- clusion criteria across studies were low cognition or dementia $[16,50,53,56-58,60,63-66,69,71,72,75,76,78$, 79], depression [57-60,71-73, 76], other major illness $[51,54,56,57,60,62,63,66,71-73,76]$, and institutionalization [16, 52, 54-56, 58, 63, 65, 66, 72, 73, 75, 78, 79]. Other exclusion criteria varied widely across studies.

\section{Exposure Assessment and Categorization}

We describe methods related to exposure assessment and categorization for each of the studies in table 2. Studies generally collected information on sleep duration based on the self report of participants [50, 52, 54, 56-59, $61-64,66-69,71,73,74,76-78]$, with the exception of eleven studies that incorporated objective measurements of sleep duration; these studies used actigraphy $[16,55$, $65,72,80]$, polysomnography $[51,53,60]$, an in-home sensor device [79], and a combination of self report and actigraphy $[70,75]$. Two different definitions of sleep duration were operationalized by these methods, with 20 studies defining sleep duration as night-time sleeping hours only $[51,53,55-57,59-64,66,67,70-72,74,75,77$, 


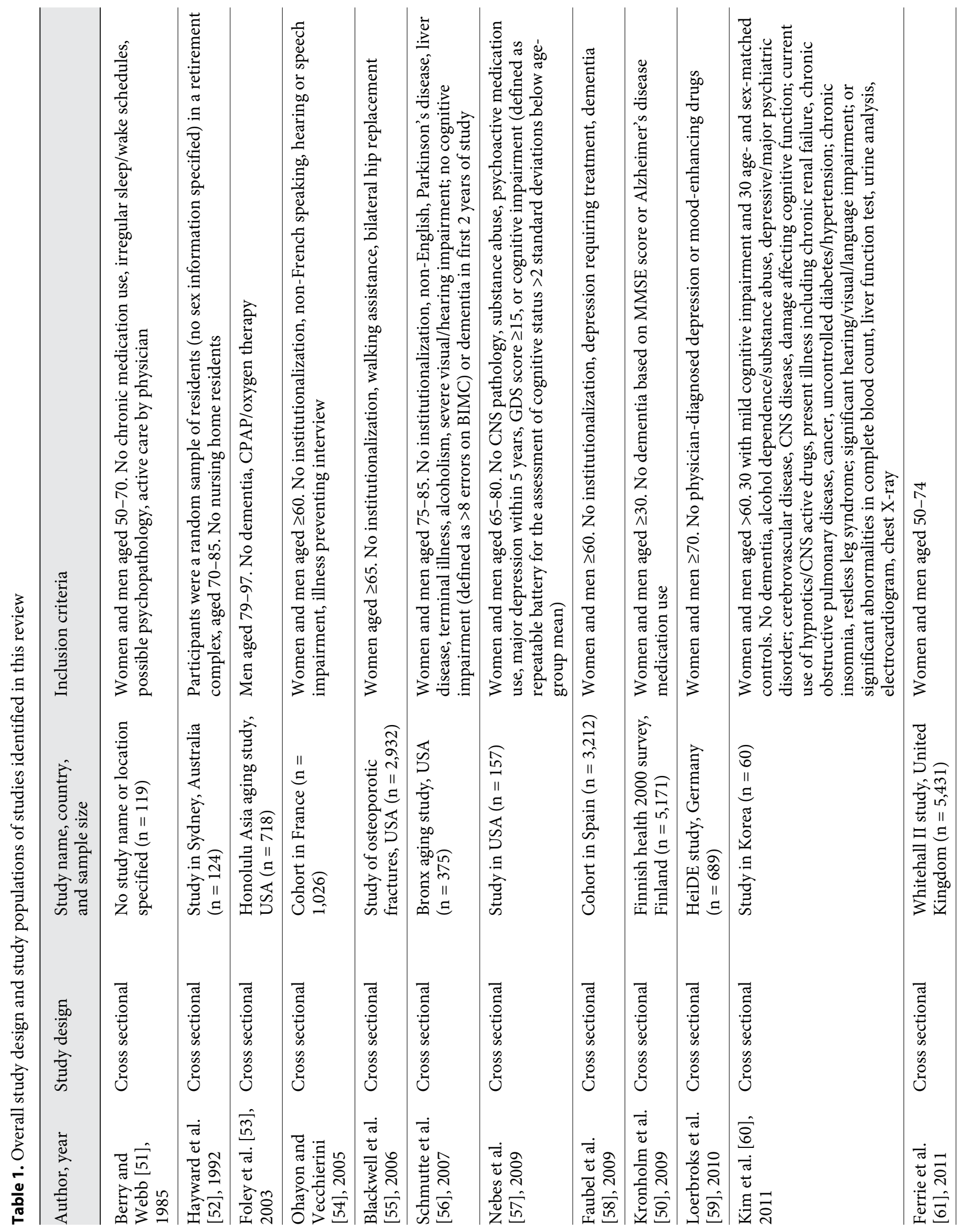




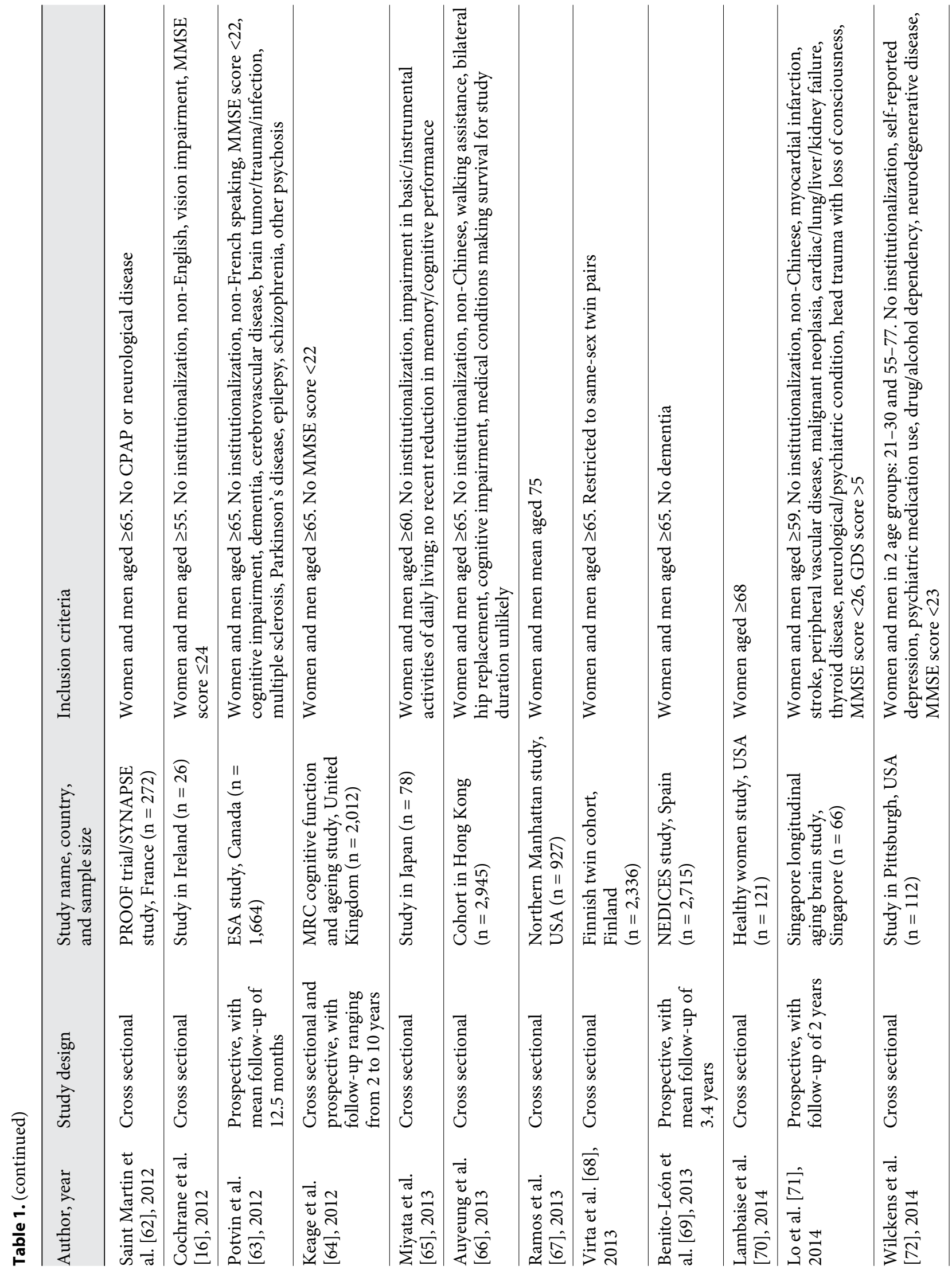




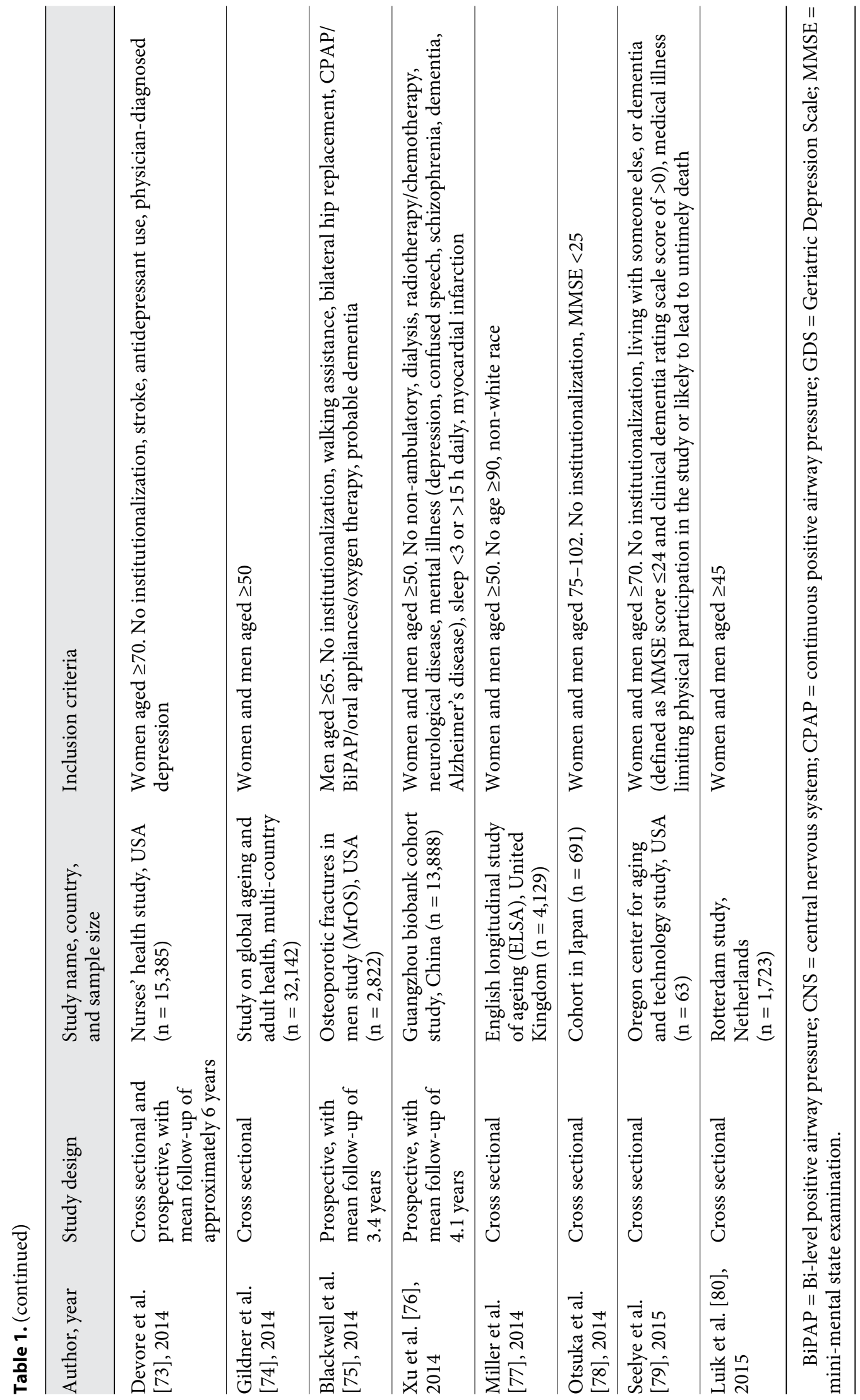




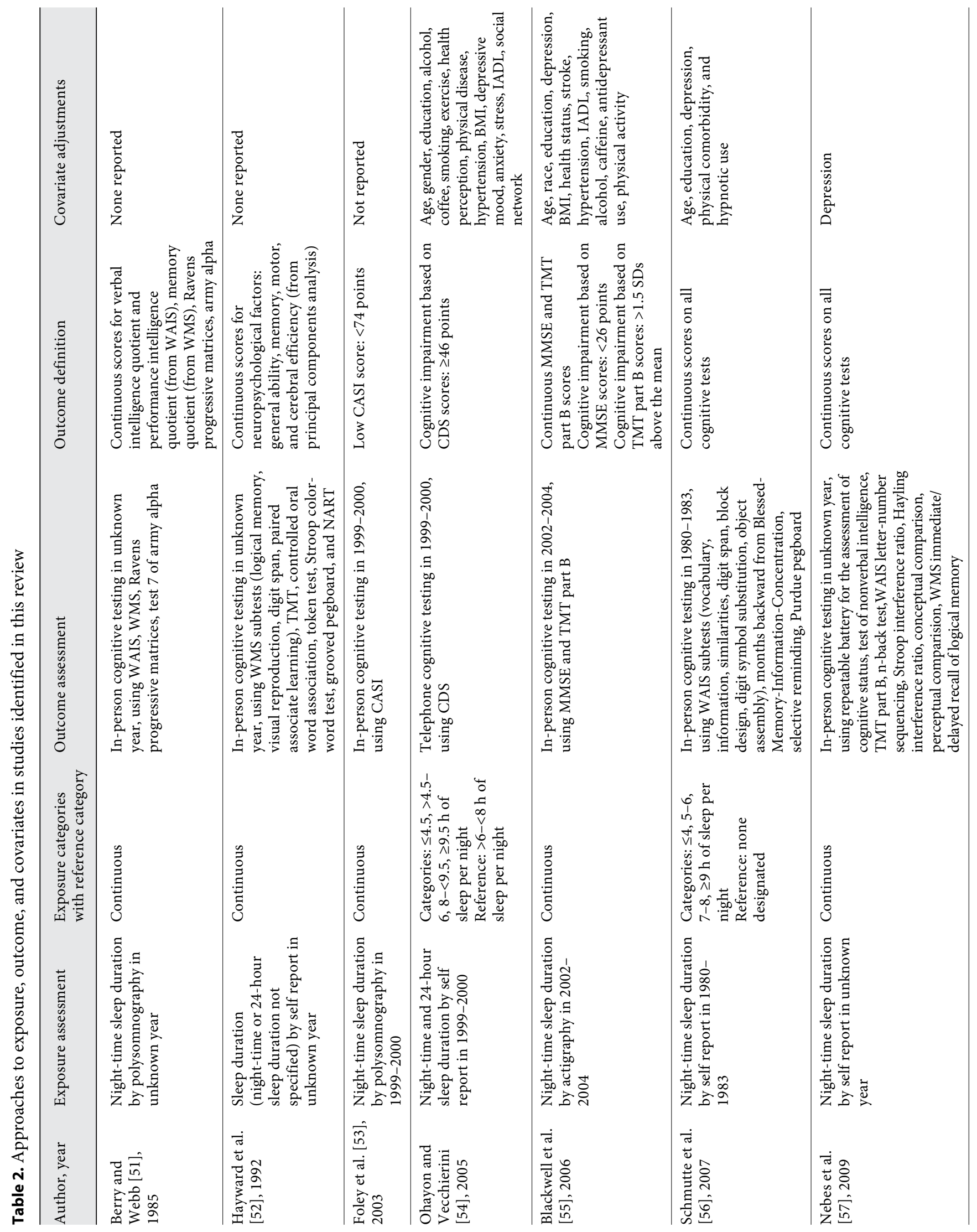




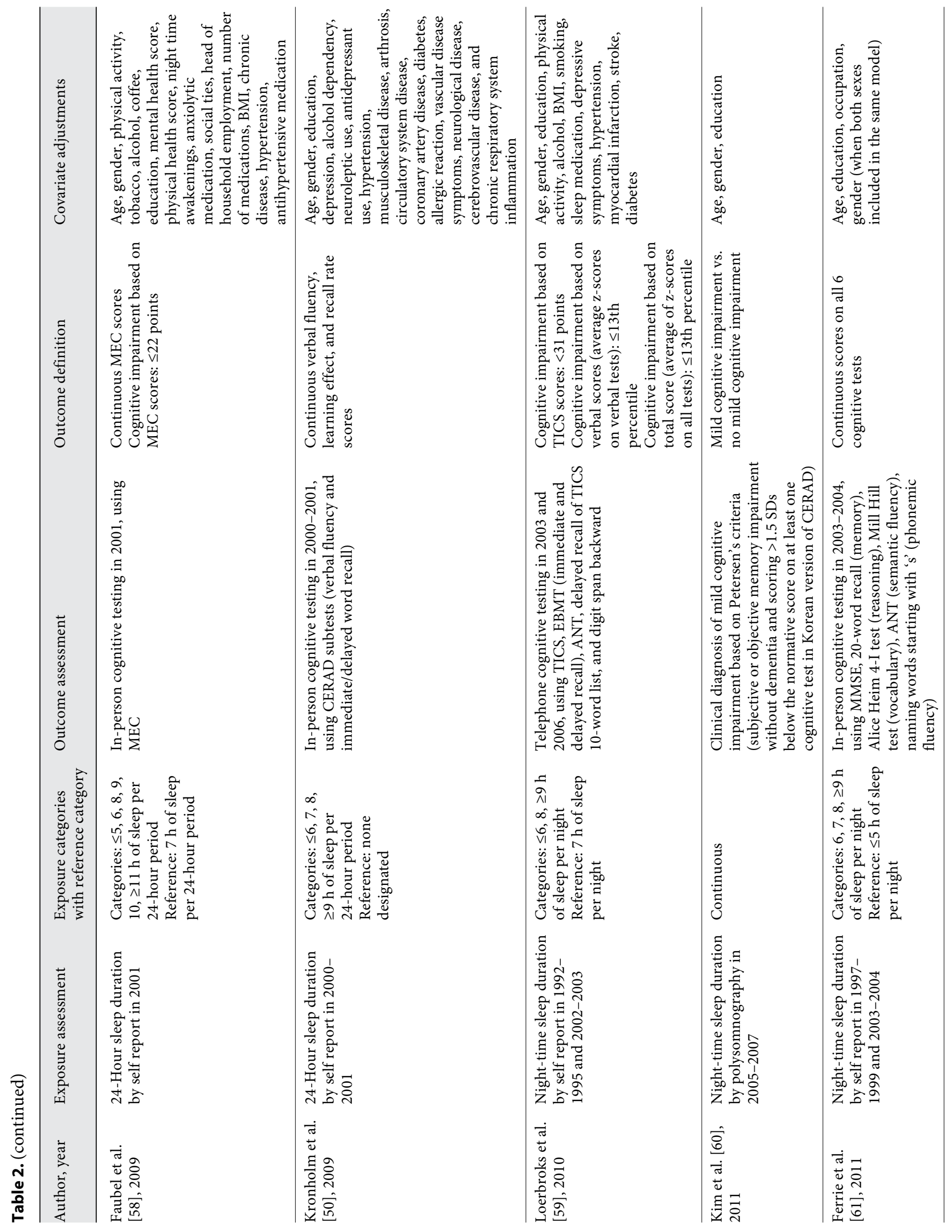




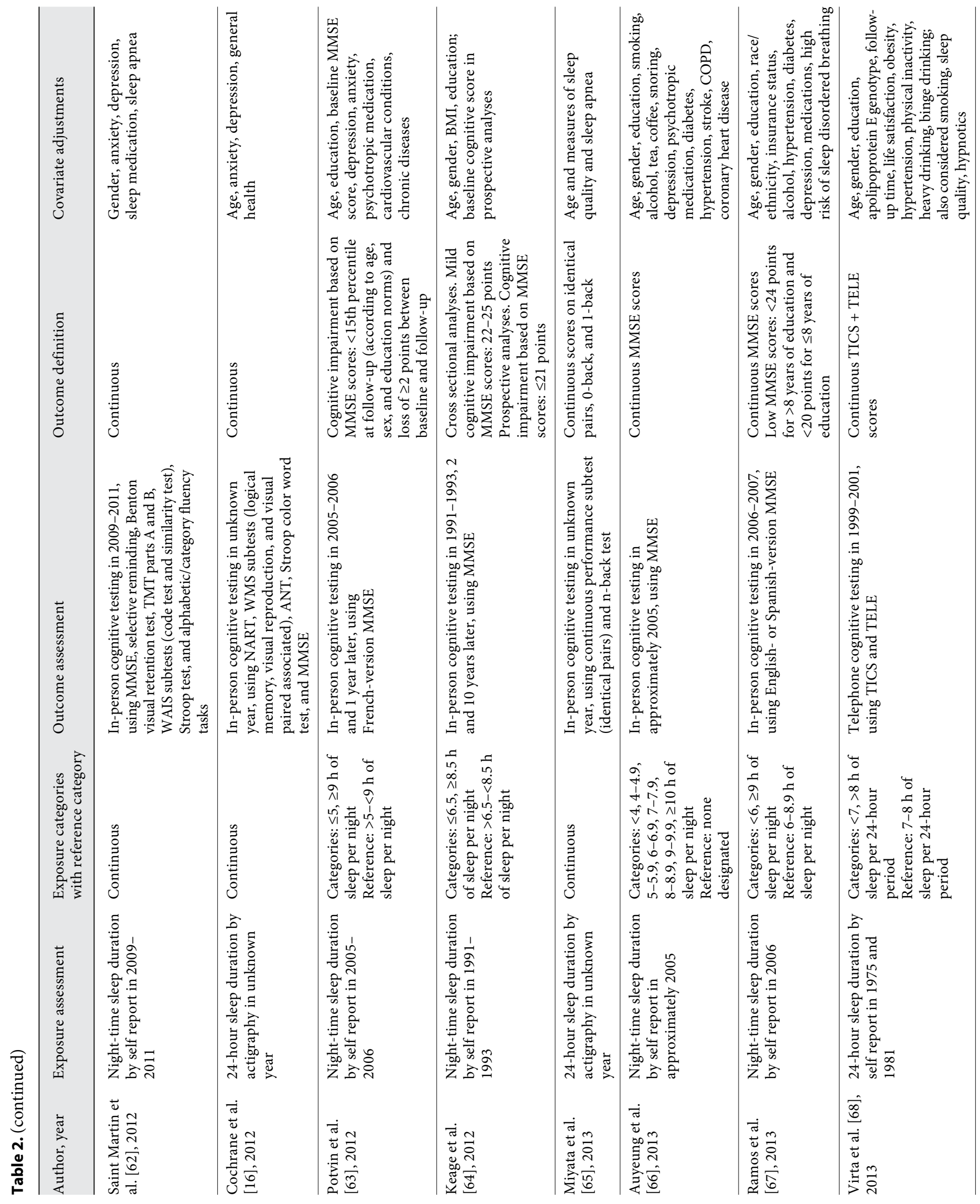




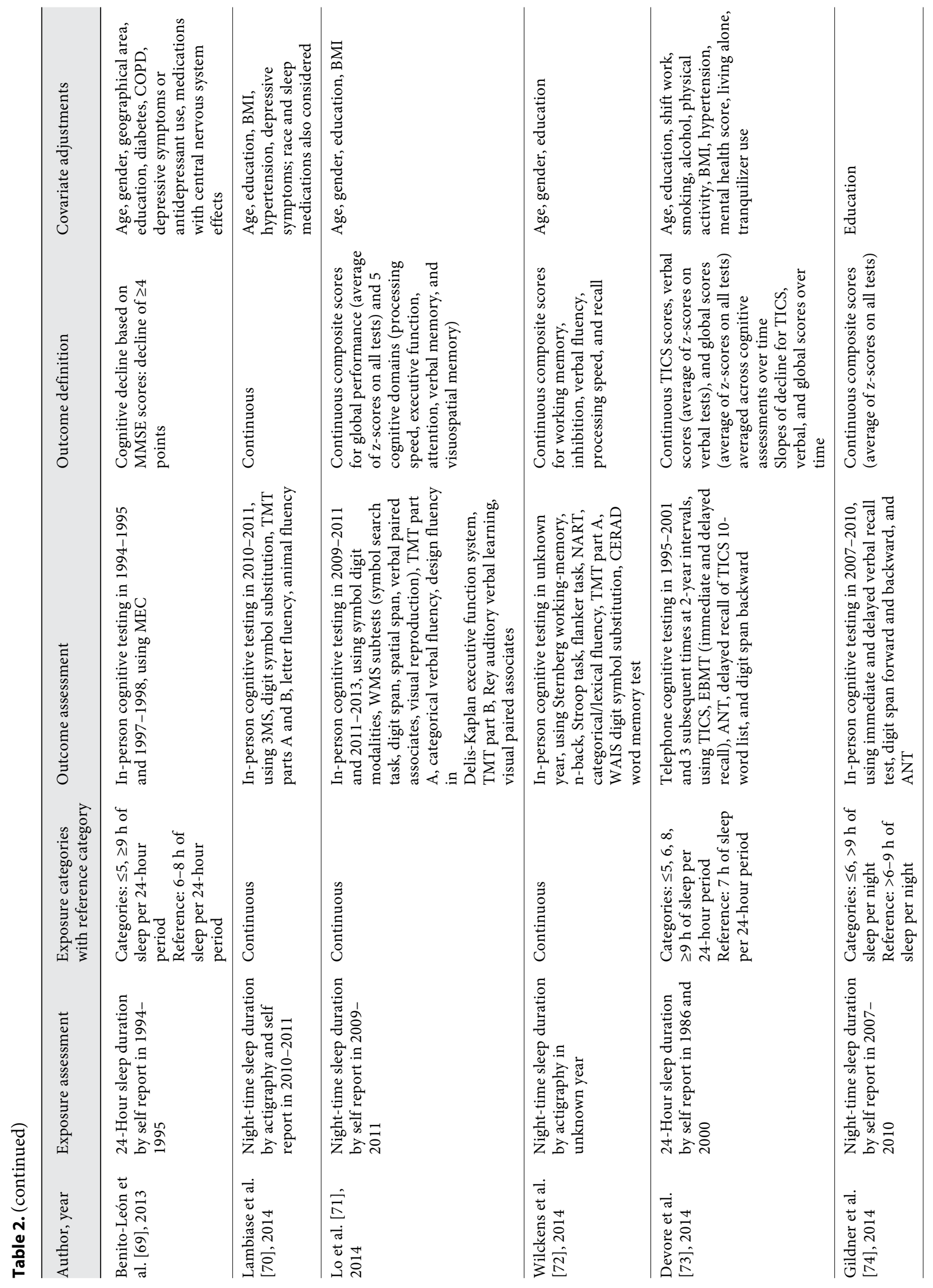




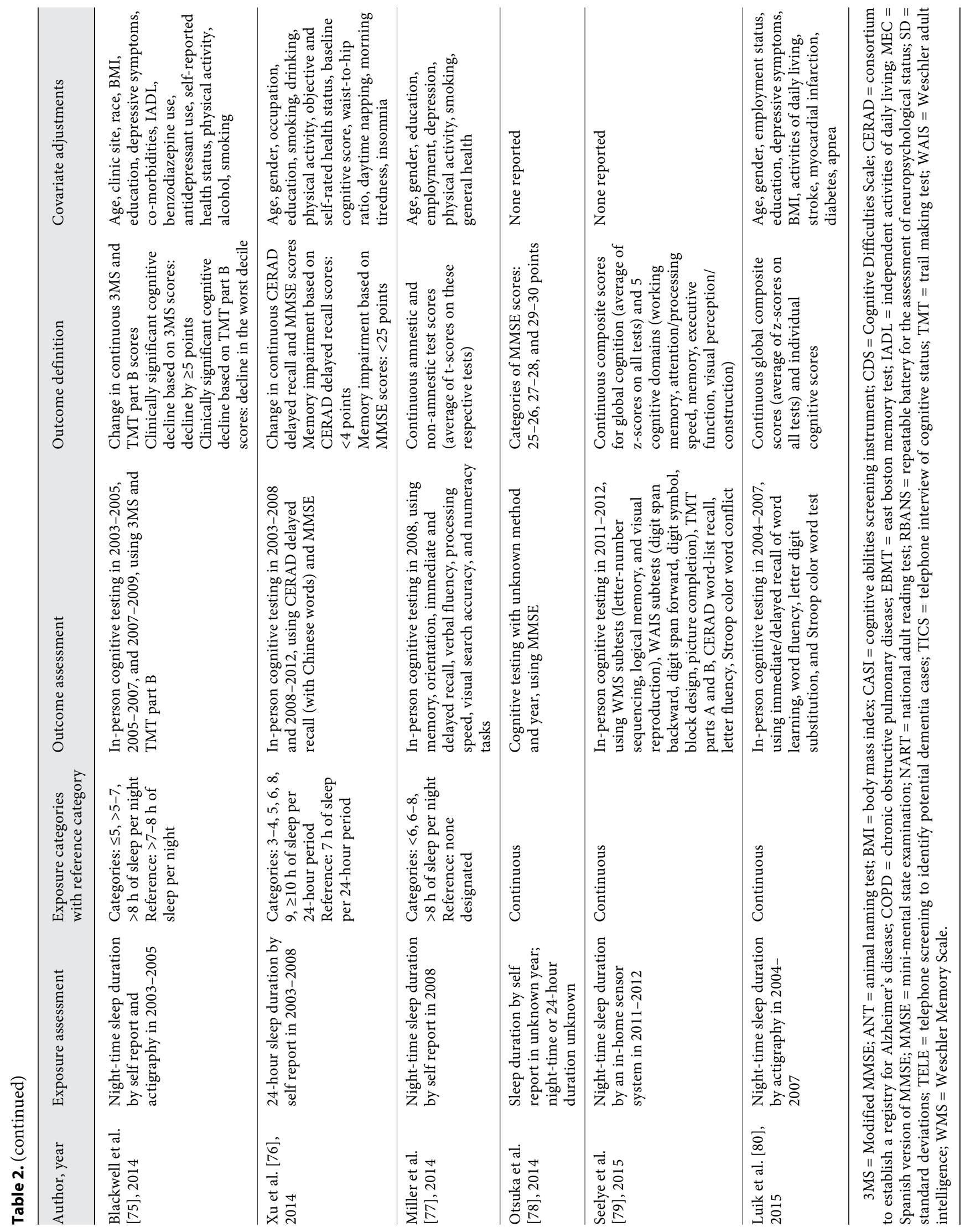


$79,80]$, and 9 studies including all sleeping hours within a 24 -hour period $[16,50,58,65,68,69,73,76]$; 1 study incorporated both of these definitions into analyses [54], and 2 studies did not provide information on the specific definition used [52, 78]. Two of these studies reported results of midlife sleep duration and cognitive function in older individuals $[68,73]$. In addition, 4 studies assessed sleep duration at 2 different time points, enabling the evaluation of changes in sleep duration over time $[59,61$, $68,73]$. Finally, sleep duration was examined categorically in some studies $[50,54,56,58,59,61,63,64,66-69$, $73-77]$, but continuously in other studies $[16,51-53,55$, $57,60,62,65,70-72,78-80]$; exposure categories and corresponding reference groups varied widely across studies.

\section{Outcome Assessments and Definitions}

We describe methods related to outcome assessment and definition for each of the studies in table 2. Most studies obtained information on cognitive function using in-person neuropsychological assessments [16, 50$53,55-58,61-67,69-72,74-77,79,80]$, although 5 studies collected this information over the telephone [54, 59, 68,73 ]; 1 study did not report whether in-person or telephone assessment was used [78] and another study made a clinical diagnosis of mild cognitive impairment [60]. Studies used a variety of different cognitive tests, although the most commonly used test was the mini mental state exam (MMSE) [16, 55, 58, 61-64, 66, 67, 69, 76, 78], the modified MMSE [70, 75], or the telephone interview of cognitive status (TICS; i.e. a telephone version of the MMSE) [59, 68, 73]; 22 studies used more than 1 cognitive test $[16,50-52,55-57,59,61,62,65,68$, $70-77,79,80]$. There was little consistency across studies in specifying how cognitive test scores were used to define the outcome of interest; in part, this stemmed from differences in tests or test batteries utilized, although cognitive outcomes were defined differently even among those studies that used the same test (e.g. the cutoff for 'cognitive impairment' based on the MMSE). As noted previously, 7 studies assessed cognitive function at more than 1 time point, which enabled the analysis of changes in cognition over time $[63,64$, $69,71,73,75,76]$.

\section{Covariates}

In table 2, we describe covariate adjustments used in statistical analyses for each of the studies. Studies generally accounted for age, gender (unless the population was restricted to one gender only), and education in their statistical models, except 5 studies that did not re- port any covariate adjustments [51-53, 78, 79]. Many studies also accounted for important health and lifestyle variables that might be confounding factors of the association between sleep duration and cognition in older adults, including alcohol intake $[50,54,55,58,59,66-68$, $73,75,76]$, physical activity $[54,55,58,59,68,73,75-$ $77]$, body mass index or obesity $[54,55,58,59,64,68$, $70,71,73,75,76,80]$, depression or antidepressant medication use $[16,50,54-57,59,62,63,66,67,69,70,75$, $77,80]$, overall health status $[16,54,55,58,75-77]$, and other co-morbidities [50, 54-56, 58, 59, 62, 63, 65-69, $73,75,80]$. Only a few studies incorporated sleep-related covariates in their analyses, including measures of sleep quality $[58,68,76]$, sleep-related medications $[56,58,59$, $62,68,70,73,75]$, and indications of sleep-disordered breathing $[62,65,67,80]$.

\section{Results of Studies on Sleep Duration and Cognitive}

Function

We describe the findings for each of the studies included in our review, separately for short and long sleep durations in relation to cognitive function, in table 3 . When short sleep durations were examined, 5 of 27 cross-sectional studies $[54,61,65,73,74]$ and 4 of 7 prospective analyses $[63,64,71,76]$ reported an association with worse cognitive function in older adults. For long sleep durations, 9 out of 27 cross-sectional studies [16, $56,58,67,68,70,73,74,78]$ and 3 of 7 prospective studies $[63,69,76]$ identified relations with worse cognition in elderly participants. All studies that reported significant associations between sleep durations and cognitive function utilized subjective assessment of sleep duration; there were no studies that found extreme objective sleep durations to be related to worse cognitive function. For example, self-reported sleep durations of 3-4 h and $\geq 10 \mathrm{~h}$ per 24 -hour period were significantly related to greater decline in cognitive scores in a large prospective study among 13,888 Chinese older adults (mean differences in MMSE change scores over 4 years $=-0.28$ points ( $95 \%$ CI -0.47 to -0.10$)$ and -0.48 points $(95 \%$ CI -0.67 to -0.28 ) for these sleep durations vs. $7 \mathrm{~h}$ of sleep in $24 \mathrm{~h}$, respectively) [76]. In contrast, a prospective study utilizing actigraphy-derived sleep durations reported that modified MMSE score decline over 3 years was similar between older participants sleeping $\leq 5$ or $>8$ h nightly compared to those sleeping $>7-8$ night-time hours (group mean scores $=-0.44$ vs. -0.34 points for $\leq 5$ vs. $>7-8 \mathrm{~h}$, and -0.48 vs. -0.34 points for $>8$ vs. $>7-8 \mathrm{~h} ; \mathrm{p} \geq$ $0.05)$ [75]. However, specific estimates were difficult to compare due to varying methods across studies, includ- 


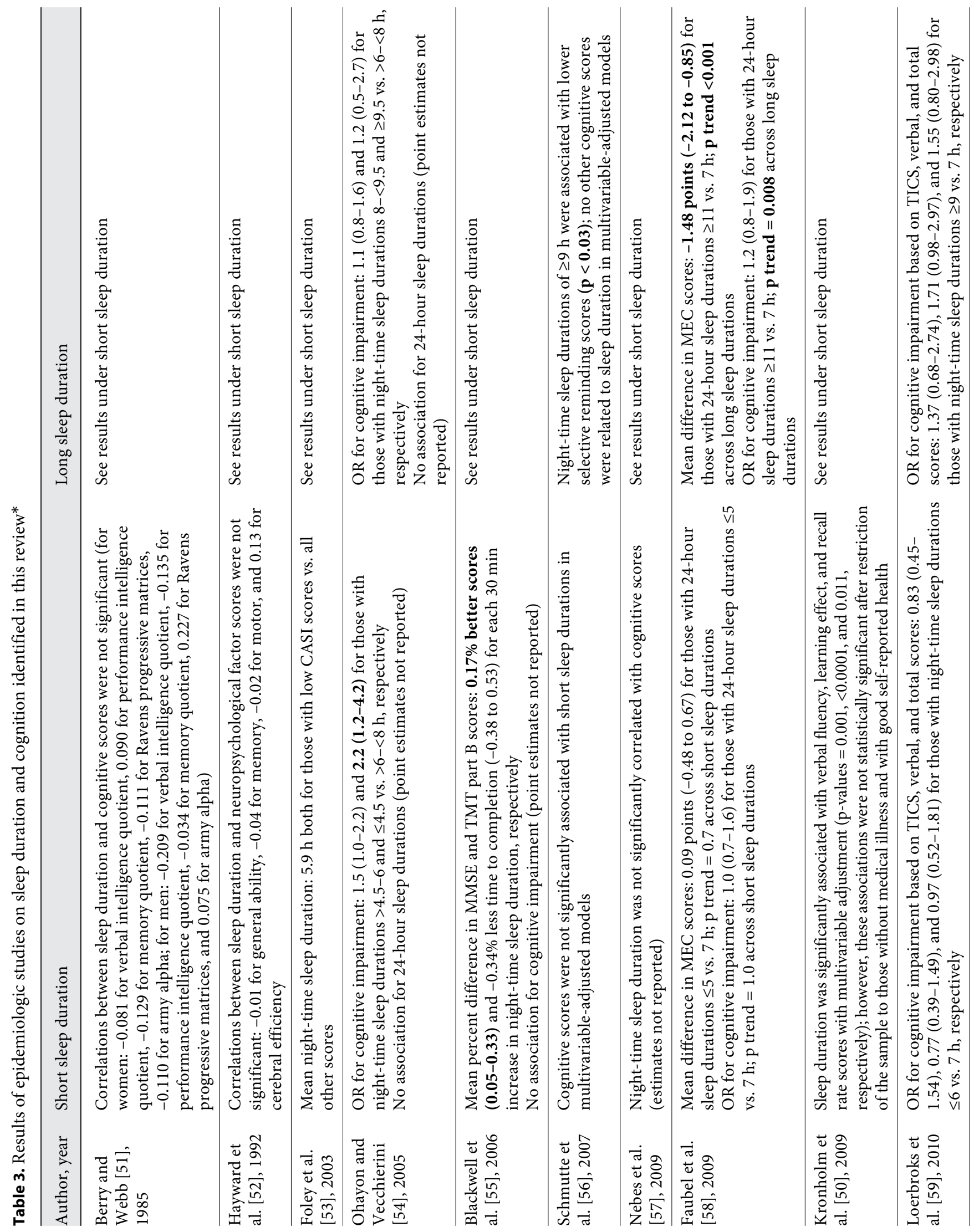




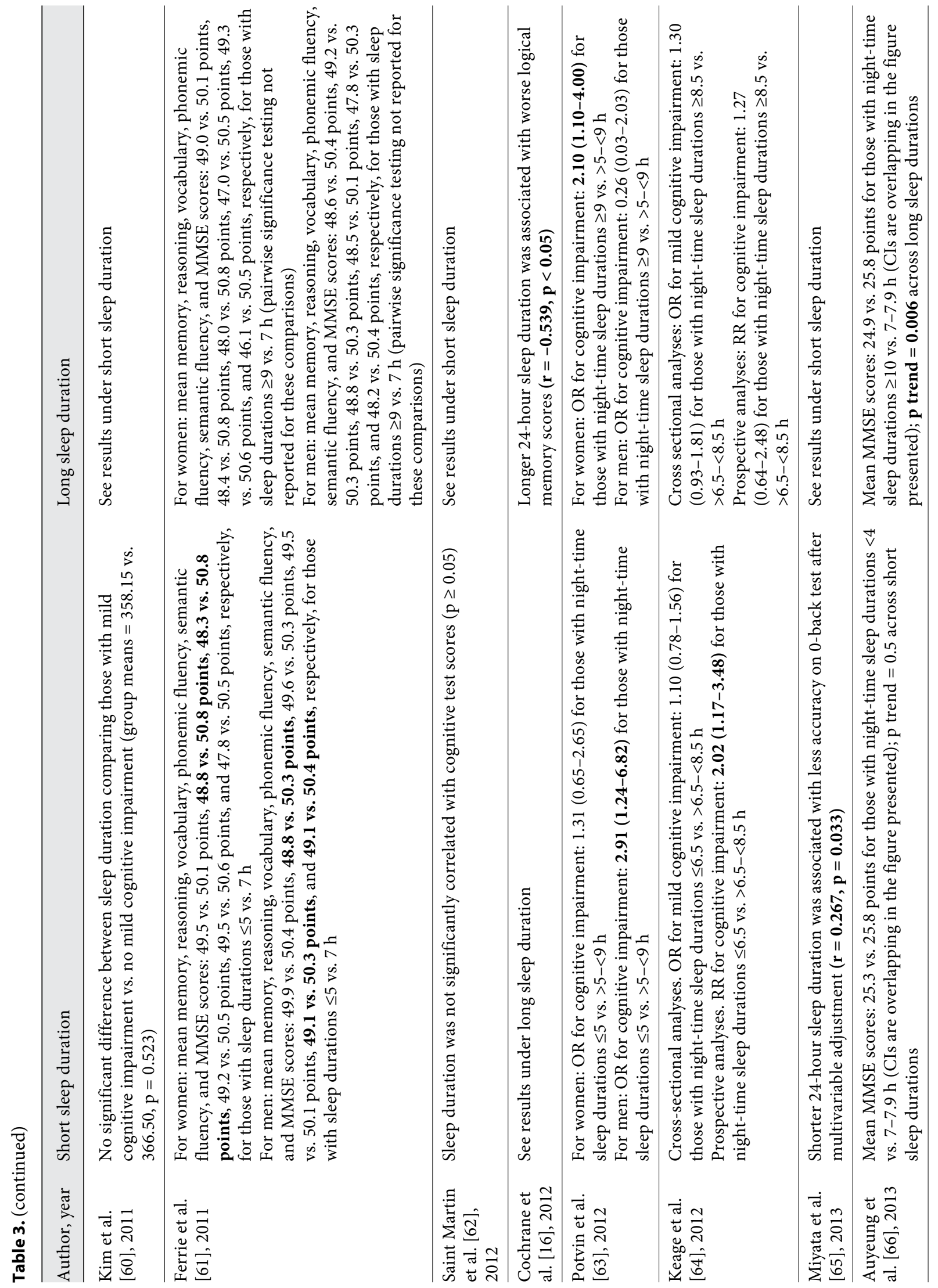




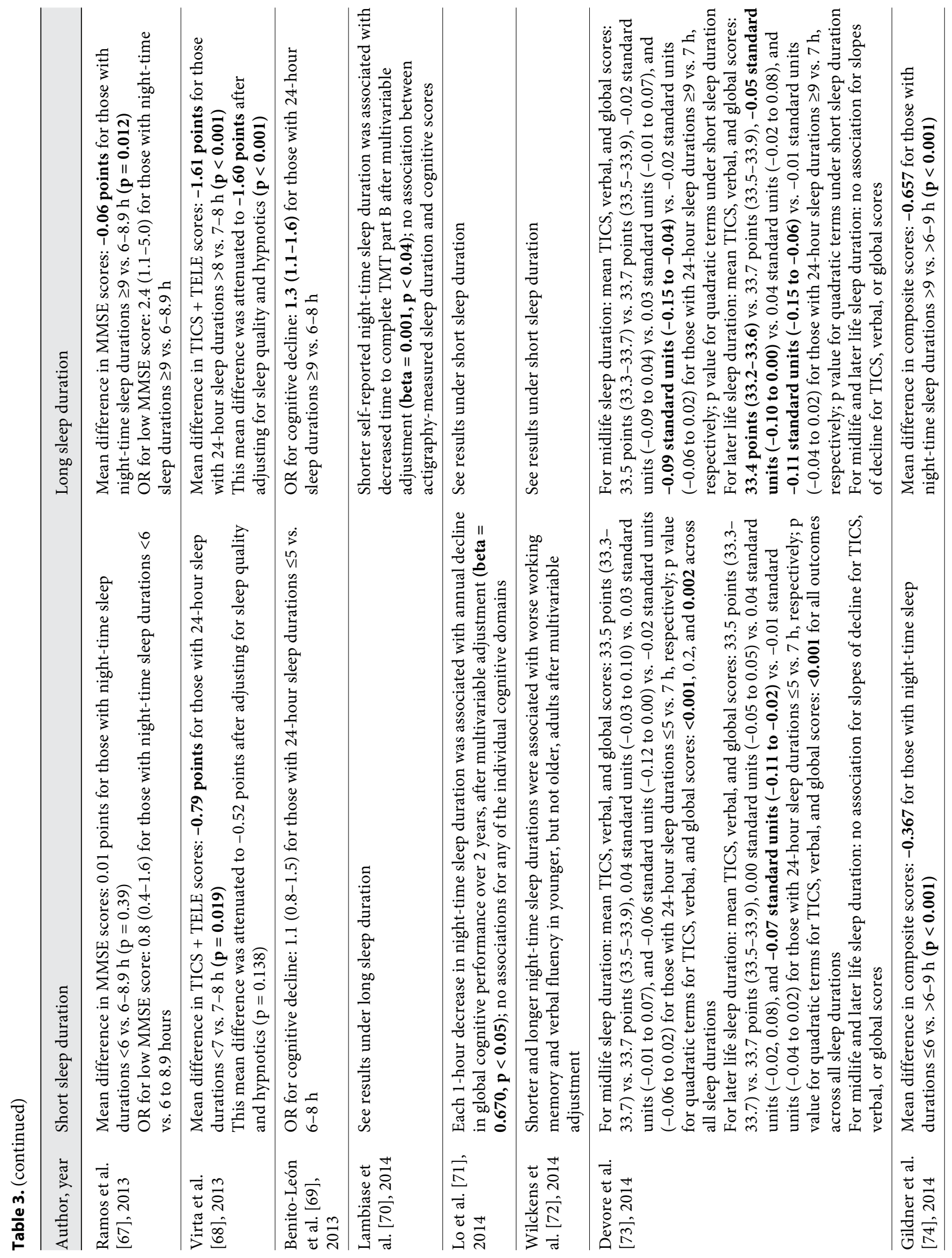




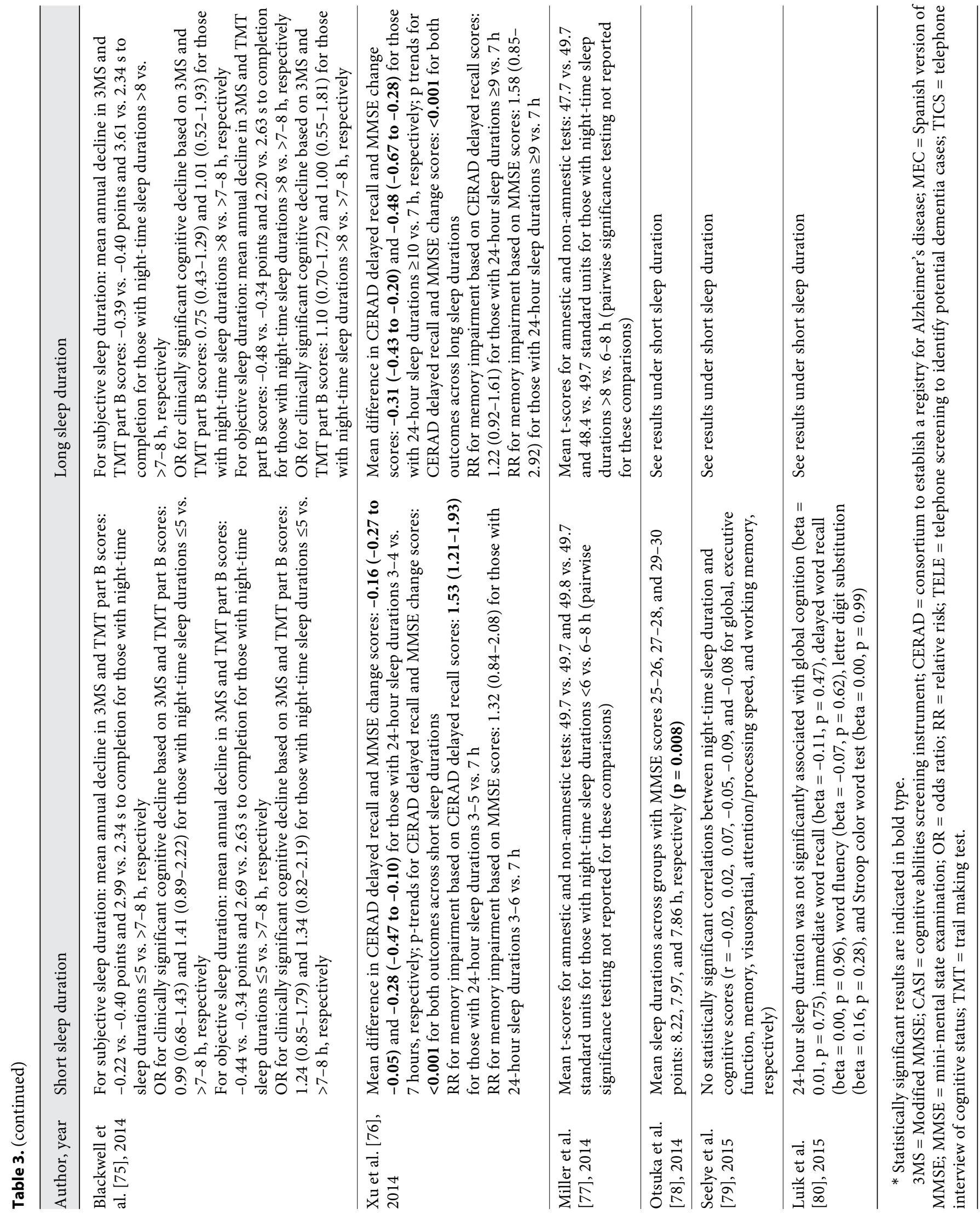


ing differences in study population, exposure assessment and categorization (including reference categories), outcome assessment and definition, and covariate adjustments.

Results of Studies on Change in Sleep Duration and Cognitive Function

We describe the results of 4 studies included in our review that examined change in sleep duration over time with cognitive function in table 4 . Three studies reported that decreased sleep duration over time was associated with lower cognitive function [61,68,73], and 4 studies found that increased sleep duration was related to worse cognition [59, 61, 68, 73]. One of these studies included prospective data on cognitive function, enabling analyses of changes in sleep duration with cognitive decline; however, there was no indication of association in these results [73]. The length of time between the first and second assessment of sleep duration in these studies ranged from 6 to 14 years.

\section{Discussion}

Based on our review, the epidemiologic literature on sleep duration and cognitive function in older adults is growing rapidly. We identified 32 existing studies of this association, of which 20 studies have been published since 2012. On average, $31 \%$ of these studies indicated associations of short sleep duration, long sleep duration, or short and long sleep durations with worse cognitive function in older individuals, with a slightly greater percentage of analyses yielding an association for long sleep durations (35\%) compared to short sleep durations (26\%). There was more consistency across 4 studies that examined changes in sleep duration over time, with each study suggesting that greater deviations from earlier life sleep duration were associated with cognition decrements in later life. There was large heterogeneity across all studies comparing their approaches to important aspects of study design, including overall study design, study population, exposure and outcome assessment, and statistical analysis (as described in the results section); thus, we did not think it was appropriate to conduct a meta-analysis of these results.

Most studies involved cross-sectional analyses of exposure and outcome data collected at the same time point, although two studies reported on midlife sleep duration assessed 1-2 decades prior to cognitive function testing $[68,73]$. There were a limited number of

Review of Sleep Duration and Cognitive Function prospective studies, with repeated cognitive assessments conducted over varying follow-up periods; however, these studies more often indicated an association between extreme sleep duration and poor cognitive function. Because prospective study designs are inherently stronger than cross-sectional ones (i.e. they provide more information about the direction of association, with less concern for bi-directional effects), this difference is somewhat intriguing. In the meantime, this body of literature should be interpreted cautiously due to its reliance on mainly cross-sectional studies. More prospective studies are clearly needed to evaluate sleep duration in relation to cognitive trajectories over time among older adults.

Studies generally assessed subjective sleep duration using self-reported information from study participants, with few studies utilizing more extensive actigraphy or polysomnography to measure objective sleep duration. Of studies that identified an association between extreme sleep durations and worse cognitive function, each ascertained subjective sleep duration via participant self report. This is interesting, considering the fact that previous studies have reported a discrepancy between subjective vs. objective assessments of sleep duration; indeed, there is some indication that older adults with perceived or actual problems with sleep quality may report more extreme sleep durations $[44,81]$. A minority of studies in this review considered sleep-related variables other than sleep duration (i.e. sleep quality, sleep medication use, and sleep-disordered breathing) as part of their statistical analyses, but one study did find that results were attenuated with adjustment for self-reported sleep quality [68]. This is consistent with two other studies included in our review that indicated objective measures of sleep disturbances, but not sleep duration, were related to worse cognitive outcomes in older adults [55, 75]; additional literature also supports a link between poor sleep quality and lower cognition in later life [24]. Clearly, more research is necessary to understand the interplay among subjective and objective sleep characteristics, and cognitive function, in older adults.

The effects of other methodologic differences across studies are more difficult to predict. First, exposure categories and corresponding reference groups varied widely across studies, leading us to characterize observed associations broadly by 'short' or 'long' sleep durations. However, we were limited in our ability to draw more detailed conclusions about specific sleep durations. Second, studies collected sleep duration information based on night time only or a 24 -hour period. The inclusion of 
Table 4. Results of epidemiologic studies on change in sleep duration and cognition identified in this review*

\begin{tabular}{|c|c|c|}
\hline Author, year & Decreased sleep duration & Increased sleep duration \\
\hline $\begin{array}{l}\text { Loerbroks et al. } \\
\text { [59], } 2010\end{array}$ & $\begin{array}{l}\text { OR for cognitive impairment based on TICS and verbal } \\
\text { scores: } 0.90(0.40-2.03) \text { and } 1.07(0.50-2.27) \text { for those } \\
\text { with a decrease vs. no change in sleep duration } \\
\text { Models for total score did not converge }\end{array}$ & $\begin{array}{l}\text { OR for cognitive impairment based on TICS and verbal } \\
\text { scores: } \mathbf{2 . 1 3}(\mathbf{1 . 0 1 - 4 . 4 8 )} \text { and } \mathbf{1 . 9 8}(\mathbf{1 . 0 4 - 3 . 7 8 )} \text { for those } \\
\text { with an increase vs. no change in sleep duration } \\
\text { Models for total score did not converge }\end{array}$ \\
\hline $\begin{array}{l}\text { Ferrie et al. [61], } \\
2011\end{array}$ & $\begin{array}{l}\text { Mean differences in memory, reasoning, vocabulary, } \\
\text { phonemic fluency, semantic fluency, and MMSE scores: } \\
-0.12(-0.80 \text { to } 0.57),-\mathbf{1 . 0 8}(-\mathbf{1 . 6 9} \text { to }-\mathbf{0 . 4 7}), \mathbf{- 0 . 7 2} \\
(-\mathbf{1 . 3 4} \text { to }-\mathbf{0 . 1 0}),-0.33(-0.99 \text { to } 0.33),-0.62(-1.27 \text { to } \\
0.02) \text {, and }-\mathbf{1 . 1 9}(-\mathbf{1 . 9 0} \text { to }-\mathbf{0 . 4 9}) \text { points for those with } \\
\text { sleep durations that decreased from } 6,7 \text {, or } 8 \text { h vs. no } \\
\text { change in sleep duration }\end{array}$ & $\begin{array}{l}\text { Mean differences in memory, reasoning, vocabulary, } \\
\text { phonemic fluency, semantic fluency, and MMSE scores: } \\
0.23(-0.61 \text { to } 1.06),-0.13 \text { ( }-0.87 \text { to } 0.61), 0.09(-0.67 \text { to } \\
0.85),-0.34(-1.15 \text { to } 0.47),-0.04(-0.82 \text { to } 0.75) \text {, and }-0.26 \\
(-1.12 \text { to } 0.60) \text { points for those with sleep durations that } \\
\text { increased from } 5 \text { or } 6 \text { hours vs. no change in sleep duration } \\
\text { Mean differences in memory, reasoning, vocabulary, } \\
\text { phonemic fluency, semantic fluency, and MMSE scores: } \\
\mathbf{- 0 . 9 8}(-\mathbf{1 . 9 6} \text { to }-\mathbf{0 . 0 1}),-\mathbf{1 . 1 1}(-\mathbf{1 . 9 8} \text { to }-\mathbf{0 . 2 5}),-\mathbf{1 . 3 9} \\
(-\mathbf{2 . 2 8} \text { to }-\mathbf{0 . 5 0}),-\mathbf{1 . 1 9}(-\mathbf{2 . 1 4} \text { to }-\mathbf{0 . 2 5}),-\mathbf{1 . 4 7}(-\mathbf{2 . 3 9} \text { to } \\
\mathbf{- 0 . 5 5}) \text {, and }-\mathbf{1 . 7 3}(-\mathbf{2 . 7 4} \text { to }-\mathbf{0 . 7 2}) \text { points for those with } \\
\text { sleep durations that increased from } 7 \text { or } 8 \text { h vs. no change } \\
\text { in sleep duration }\end{array}$ \\
\hline
\end{tabular}

Virta et al. [68], Significantly lower TICS + TELE scores observed in 2013 those with 24-hour sleep durations $<7$ h in 1975 or 1981 and those with 24-hour sleep durations $<7 \mathrm{~h}$ in 1975 and 1981 vs. 7-8 h in both years (point estimate not reported)

Devore et al. Mean TICS, verbal, and global scores: 33.4 points (33.2-

[73], $2014 \quad 33.6)$ vs. 33.7 points (33.5-33.9), 0.00 standard units ( -0.06 to 0.06$)$ vs. 0.05 standard units ( -0.02 to 0.09 ), and $\mathbf{- 0 . 0 8}$ standard units $(-\mathbf{0 . 1 3}$ to $-\mathbf{0 . 0 2})$ vs. -0.02 standard units ( -0.06 to 0.02 ) for those with a decrease in 24-hour sleep duration $\geq 2 \mathrm{~h}$ vs. no change; $\mathrm{p}$ value for quadratic terms for TICS, verbal, and global scores: $<\mathbf{0 . 0 0 1}$ for all outcomes across all change in sleep categories

No association for slopes of decline for TICS, verbal, or global scores
Significantly lower TICS + TELE scores observed in those with 24-hour sleep durations $>8 \mathrm{~h}$ in 1975 or 1981 and those with 24-hour sleep durations $>8 \mathrm{~h}$ in 1975 and 1981 vs. $7-8 \mathrm{~h}$ in both years (point estimates not reported)

Mean TICS, verbal, and global scores: 33.3 points (33.133.5) vs. 33.7 points (33.5-33.9), $\mathbf{- 0 . 0 4}$ standard units $\mathbf{( - \mathbf { 0 . 1 0 }}$ to $\mathbf{0 . 0 2})$ vs. 0.05 standard units $(-0.02$ to 0.09$)$, and $\mathbf{- 0 . 1 2}$ standard units $(-\mathbf{0 . 1 7}$ to $-\mathbf{0 . 0 7})$ vs. -0.02 standard units ( -0.06 to 0.02$)$ for those with an increase in 24-hour sleep duration $\geq 2 \mathrm{~h}$ vs. no change; $\mathrm{p}$ value for quadratic terms under decreased sleep duration

No association for slopes of decline for TICS, verbal, or global scores

* Statistically significant results are indicated in bold type.

TELE = Telephone screening to identify potential dementia cases; TICS = telephone interview of cognitive status; MMSE = mini-mental state examination; $\mathrm{OR}=$ odds ratio.

daytime napping hours in total sleep duration over $24 \mathrm{~h}$ might be most likely to increase sleep durations for individuals on the shorter end of the spectrum, although it is perhaps just as likely that those who take regular daytime naps are the most fragmented sleepers, which could increase sleep durations among very short and very long sleepers because both groups tend to have more fragmented sleep. However, in this review, we did not observe trends in study findings according to this difference. Likewise, there were large differences in methods of cognitive assessment and outcome definition across studies, but findings were not systematically different based on these factors.

Third, most studies accounted for covariates that might influence the association between sleep duration and cognition among older individuals. Potential confounders are factors that affect both exposure and outcome, with the possibility of inducing a non-causal (biased) association. Most studies accounted for such factors by excluding individuals with certain characteristics from the study population (e.g. depression or other co-morbidities) or by adjusting for these characteristics in statis- 
tical analyses. In addition to comorbidities, other factors that might confound the association of sleep duration and cognitive function include age, alcohol intake, body mass index, physical activity, and sleep-related factors. Although most studies accounted for some of these factors, these adjustments varied across studies and the potential for residual confounding remains in all observational studies; in particular, sleep-related factors were not accounted for in most studies. There is also the possibility that health and lifestyle factors might be mediators of this association, which would suggest that controlling for these factors could attenuate part of the association of interest. For studies that yielded different results before and after inclusion of these factors, it is probably most appropriate to control for possible confounding effects and interpret results accordingly, with the understanding that some associations may be underestimated. Thus, we interpreted results based on estimates adjusted for key potential confounders.

There may be several biologic explanations for studies that observed associations between extreme sleep durations and worse cognitive function in older adults. The central pacemaker for circadian rhythms is located in the suprachiasmatic nuclei of the brain, and circadian rhythms are important for optimal sleeping patterns and cognitive function [83]. However, circadian rhythms tend to weaken with aging, such that sleep and cognition can become dysregulated in older adults [84]. Thus, observed associations between sleep disturbances (including extreme sleep durations) and worse cognitive function in elderly individuals could be driven, at least in part, by this common factor. Moreover, sleeping patterns and Alzheimer's disease pathology may interact in a bidirectional manner [22]. It is known that Alzheimer's disease, even in stages of early cognitive impairment, induces sleep disturbances that become more pronounced with disease progression $[22,85]$.

However, recent studies have supported the notion that sleep disturbances can also promote beta-amyloid accumulation (the hallmark pathology of Alzheimer's disease) in the absence of cognitive impairment and Alzheimer's disease. One study found that sleep deprivation and poor sleep quality promoted beta-amyloid accumulation in mouse brain [20], while human studies identified self-reported short sleep duration, worse sleep efficiency, and frequent daytime napping as being associated with greater beta-amyloid burden in older adults $[21,32]$. An additional study reported that greater sleep fragmentation was associated with a higher risk of cognitive decline and Alzheimer's disease in the elderly popu-

Review of Sleep Duration and Cognitive Function lation [86]. Further research on the sleep-wake cycle and beta-amyloid dynamics supports these observations, suggesting a diurnal pattern of beta-amyloid clearance with sleep and beta-amyloid accumulation with wakefulness in both mice and human brains $[20,23]$. On a molecular level, it appears that sleep disturbances could induce neuronal excitability via altered potassium currents, leading to beta-amyloid accumulation [87]. Thus, there is growing evidence to support a central role of beta-amyloid accumulation in explaining associations between sleep disturbances and cognitive impairment. Still, other studies implicate increased tau protein, neuroinflammation, neurodegeneration, hypoxia, and vascular changes, as well as decreased synaptic plasticity as mediators of this association, any of which may also interact with beta-amyloid to promote further cognitive decrements [24, 88].

Interestingly, the Osteoporotic Fractures in Men Study suggests that self-reported extreme sleep durations may be a marker for objective sleep disturbances. In this study, wake after sleep onset (an objective measure of sleep disruption) was significantly higher among participants with the shortest and longest self-reported sleep durations (average wake-after-sleep-onset times: 85.4, 75.6, 78.4 , and $93.0 \mathrm{~min}$ for individuals with night-time sleep durations $\leq 5,>5-7,>7-8$, and $>8$ h, respectively; $\mathrm{p}<$ 0.001) [44]. The authors posited that individuals with self-reported long sleep might perceive their sleep as long due to multiple night awakenings, or because they spend long periods in bed (although they are not necessarily sleeping). If this were true, then the link between sleep disturbances and beta-amyloid accumulation could help explain observed associations between extremes of selfreported sleep duration and worse cognitive function in observational studies of older adults. It might also contribute to our understanding of studies that did not find objectively measured extreme sleep durations to be associated with lower cognition, as these studies eliminate the influence of sleep quality on an individual's perception of sleep duration.

In conclusion, there is increased attention being paid to associations between sleep duration and cognitive function in older populations. Existing observational studies have produced mixed results, but epidemiologic research on objective sleep assessments and later-life cognition has begun to enhance our understanding of these findings. Future observational studies incorporating such assessments are clearly necessary, and may help elucidate potential biologic mechanisms of these associations. Intervention studies will also be needed to identify effective 
strategies (e.g. improved sleep hygiene, increased physical activity, and sleep-promoting medications) [88] for ameliorating cognitive impairment among affected individuals, and preventing cognitive decrements among those not yet affected.

\section{Acknowledgments and Funding}

The authors did not receive funding for this research, and they report no conflicts of interest.

\section{References}

1 Wang XS, Armstrong ME, Cairns BJ, Key TJ, Travis RC: Shift work and chronic disease: the epidemiological evidence. Occup Med (Lond) 2011;61:78-89.

2 Akerstedt T, Kecklund G, Johansson SE: Shift work and mortality. Chronobiol Int 2004;21: 1055-1061.

3 Cappuccio FP, D’Elia L, Strazzullo P, Miller MA: Quantity and quality of sleep and incidence of type 2 diabetes: a systematic review and meta-analysis. Diabetes Care 2010;33: 414-420.

4 Zizi F, Jean-Louis G, Brown CD, Ogedegbe G, Boutin-Foster C, McFarlane SI: Sleep duration and the risk of diabetes mellitus: epidemiologic evidence and pathophysiologic insights. Curr Diab Rep 2010;10:43-47.

5 Touma C, Pannain S: Does lack of sleep cause diabetes? Cleve Clin J Med 2011;78: 549-558.

6 Knutson KL: Sleep duration and cardiometabolic risk: a review of the epidemiologic evidence. Best Pract Res Clin Endocrinol Metab 2010;24:731-743.

7 Cappuccio FP, Cooper D, D’Elia L, Strazzullo P, Miller MA: Sleep duration predicts cardiovascular outcomes: a systematic review and meta-analysis of prospective studies. Eur Heart J 2011;32:1484-1492.

8 Nagai M, Hoshide S, Kario K: Sleep duration as a risk factor for cardiovascular disease - a review of the recent literature. Curr Cardiol Rev 2010;6:54-61.

9 Cappuccio FP, D’Elia L, Strazzullo P, Miller MA: Sleep duration and all-cause mortality: a systematic review and meta-analysis of prospective studies. Sleep 2010;33:585-592.

10 Gallicchio L, Kalesan B: Sleep duration and mortality: a systematic review and meta-analysis. J Sleep Res 2009;18:148-158.

11 Gorelick PB, Scuteri A, Black SE, Decarli C, Greenberg SM, Iadecola C, Launer LJ, Laurent S, Lopez OL, Nyenhuis D, Petersen RC, Schneider JA, Tzourio C, Arnett DK, Bennett DA, Chui HC, Higashida RT, Lindquist R, Nilsson PM, Roman GC, Sellke FW, Seshadri S: Vascular contributions to cognitive impairment and dementia: a statement for healthcare professionals from the American heart association/American stroke association. Stroke 2011;42:26722713.

12 Cho K, Ennaceur A, Cole JC, Suh CK: Chronic jet lag produces cognitive deficits. J Neurosci 2000;20:RC66.
13 Cho K: Chronic 'jet lag' produces temporal lobe atrophy and spatial cognitive deficits. Nat Neurosci 2001;4:567-568.

14 Machi MS, Staum M, Callaway CW, Moore C, Jeong K, Suyama J, Patterson PD, Hostler D: The relationship between shift work, sleep, and cognition in career emergency physicians. Acad Emerg Med 2012;19:85-91.

15 Oosterman JM, van Someren EJ, Vogels RL, Van Harten B, Scherder EJ: Fragmentation of the rest-activity rhythm correlates with agerelated cognitive deficits. J Sleep Res 2009;18: 129-135.

16 Cochrane A, Robertson IH, Coogan AN: Association between circadian rhythms, sleep and cognitive impairment in healthy older adults: an actigraphic study. J Neural Transm (Vienna) 2012;119:1233-1239.

17 Tranah GJ, Blackwell T, Stone KL, AncoliIsrael S, Paudel ML, Ensrud KE, Cauley JA, Redline S, Hillier TA, Cummings SR, Yaffe K; SOF Research Group: Circadian activity rhythms and risk of incident dementia and mild cognitive impairment in older women. Ann Neurol 2011;70:722-732.

18 Walsh CM, Blackwell T, Tranah GJ, Stone KL, Ancoli-Israel S, Redline S, Paudel M, Kramer $\mathrm{JH}$, Yaffe K: Weaker circadian activity rhythms are associated with poorer executive function in older women. Sleep 2014;37: 2009-2016.

19 Riemersma-van der Lek RF, Swaab DF, Twisk J, Hol EM, Hoogendijk WJ, Van Someren EJ: Effect of bright light and melatonin on cognitive and noncognitive function in elderly residents of group care facilities: a randomized controlled trial. JAMA 2008;299:26422655.

20 Kang JE, Lim MM, Bateman RJ, Lee JJ, Smyth LP, Cirrito JR, Fujiki N, Nishino S, Holtzman DM: Amyloid-beta dynamics are regulated by orexin and the sleep-wake cycle. Science 2009; 326:1005-1007.

21 Spira AP, Gamaldo AA, An Y, Wu MN, Simonsick EM, Bilgel M, Zhou Y, Wong DF, Ferrucci L, Resnick SM: Self-reported sleep and $\beta$-amyloid deposition in communitydwelling older adults. JAMA Neurol 2013;70: 1537-1543.

22 Ju YE, Lucey BP, Holtzman DM: Sleep and Alzheimer disease pathology - a bidirectional relationship. Nat Rev Neurol 2014;10:115119.

23 Huang Y, Potter R, Sigurdson W, Santacruz A, Shih S, Ju YE, Kasten T, Morris JC, Mintun
M, Duntley S, Bateman RJ: Effects of age and amyloid deposition on a $\beta$ dynamics in the human central nervous system. Arch Neurol 2012;69:51-58.

24 Yaffe K, Falvey CM, Hoang T: Connections between sleep and cognition in older adults. Lancet Neurol 2014;13:1017-1028.

25 Moher D, Liberati A, Tetzlaff J, Altman DG; PRISMA Group: Preferred reporting items for systematic reviews and meta-analyses: the PRISMA statement. Ann Intern Med 2009; 151:264-269, W64.

26 Sampaio RA, Sewo Sampaio PY, Yamada M, Tsuboyama T, Arai H: Self-reported quality of sleep is associated with bodily pain, vitality and cognitive impairment in Japanese older adults. Geriatr Gerontol Int 2014;14:628635.

27 Dlugaj M, Weinreich G, Weimar C, Stang A, Dragano N, Wessendorf TE, Teschler $\mathrm{H}$, Winkler A, Wege N, Moebus S, Möhlenkamp S, Erbel R, Jöckel KH; Heinz Nixdorf Recall Study Investigative Group: Sleep-disordered breathing, sleep quality, and mild cognitive impairment in the general population. J Alzheimers Dis 2014;41:479-497.

28 Chang-Quan H, Bi-Rong D, Yan Z: Association between sleep quality and cognitive impairment among Chinese nonagenarians/ centenarians. J Clin Neurophysiol 2012;29: 250-255.

29 Qureshi SS, Ansari B, Qureshi MA, Zohra RR: The relationship between sleep and cognitive functioning in adult people. Pak J Pharm Sci 2014;27:2153-2156.

30 Wilckens KA, Woo SG, Erickson KI, Wheeler ME: Sleep continuity and total sleep time are associated with task-switching and preparation in young and older adults. J Sleep Res 2014;23:508-516.

31 Amer MS, Hamza SA, El Akkad RM, Abdel Galeel YI: Does self-reported sleep quality predict poor cognitive performance among elderly living in elderly homes? Aging Ment Health 2013;17:788-792.

32 Ju YE, McLeland JS, Toedebusch CD, Xiong C, Fagan AM, Duntley SP, Morris JC, Holtzman DM: Sleep quality and preclinical Alzheimer disease. JAMA Neurol 2013;70: 587-593.

33 Jaussent I, Bouyer J, Ancelin ML, Berr C, Foubert-Samier A, Ritchie K, Ohayon MM, Besset A, Dauvilliers Y: Excessive sleepiness is predictive of cognitive decline in the elderly. Sleep 2012;35:1201-1207. 
34 Scullin MK: Sleep, memory, and aging: the link between slow-wave sleep and episodic memory changes from younger to older adults. Psychol Aging 2013;28:105-114.

35 Sutter C, Zöllig J, Allemand M, Martin M: Sleep quality and cognitive function in healthy old age: the moderating role of subclinical depression. Neuropsychology 2012;26:768-775.

36 Westerberg CE, Lundgren EM, Florczak SM, Mesulam MM, Weintraub S, Zee PC, Paller KA: Sleep influences the severity of memory disruption in amnestic mild cognitive impairment: results from sleep self-assessment and continuous activity monitoring. Alzheimer Dis Assoc Disord 2010;24:325-333.

37 Aly M, Moscovitch M: The effects of sleep on episodic memory in older and younger adults. Memory 2010;18:327-334.

38 Merlino G, Piani A, Gigli GL, Cancelli I, Rinaldi A, Baroselli A, Serafini A, Zanchettin B, Valente M: Daytime sleepiness is associated with dementia and cognitive decline in older Italian adults: a population-based study. Sleep Med 2010;11:372-377.

39 Tafaro L, Cicconetti P, Baratta A, Brukner N, Ettorre E, Marigliano V, Cacciafesta M: Sleep quality of centenarians: cognitive and survival implications. Arch Gerontol Geriatr 2007; 44(suppl 1):385-389.

40 Jelicic M, Bosma H, Ponds RW, Van Boxtel MP, Houx PJ, Jolles J: Subjective sleep problems in later life as predictors of cognitive decline. Report from the Maastricht ageing study (MAAS). Int J Geriatr Psychiatry 2002; 17:73-77.

41 Foley D, Monjan A, Masaki K, Ross W, Havlik $\mathrm{R}$, White L, Launer L: Daytime sleepiness is associated with 3-year incident dementia and cognitive decline in older Japanese-American men. J Am Geriatr Soc 2001;49:1628-1632.

42 Cole CS, Richards KC, Beck CC, Roberson PK, Lambert C, Furnish A, Free J, Tackett J: Relationships among disordered sleep and cognitive and functional status in nursing home residents. Res Gerontol Nurs 2009;2: 183-191.

43 McHugh JE, Walsh L, Lawlor BA: Time to bed is associated with cognitive outcome: an analysis of sleep-times and wake-times in community-dwelling older adults. Biol Rhythm Res 2014;45:103-114.

44 Blackwell T, Yaffe K, Ancoli-Israel S, Redline S, Ensrud KE, Stefanick ML, Laffan A, Stone KL; Osteoporotic Fractures in Men (MrOS) Study Group: Association of sleep characteristics and cognition in older communitydwelling men: the MrOS sleep study. Sleep 2011;34:1347-1356.

45 Tworoger SS, Lee S, Schernhammer ES, Grodstein F: The association of self-reported sleep duration, difficulty sleeping, and snoring with cognitive function in older women. Alzheimer Dis Assoc Disord 2006; 20:41-48.

$46 \mathrm{Xu} \mathrm{L}$, Jiang CQ, Lam TH, Liu B, Jin YL, Zhu T, Zhang WS, Cheng KK, Thomas GN: Short or long sleep duration is associated with memory impairment in older Chinese: the Guangzhou Biobank Cohort Study. Sleep 2011;34:575-580

47 Ohayon MM, Vecchierini MF: Daytime sleepiness and cognitive impairment in the elderly population. Arch Intern Med 2002;162: 201-208.

48 Adam AM, Potvin O, Callahan BL, Bastien C, Lorrain D, Desjardins S, Forget H, Préville M, Hudon C: Subjective sleep quality in non-demented older adults with and without cognitive impairment. Int $\mathrm{J}$ Geriatr Psychiatry 2014;29:970-977.

49 Hayes TL, Riley T, Mattek N, Pavel M, Kaye JA: Sleep habits in mild cognitive impairment. Alzheimer Dis Assoc Disord 2014;28:145150.

50 Kronholm E, Sallinen M, Suutama T, Sulkava R, Era P, Partonen T: Self-reported sleep duration and cognitive functioning in the general population. J Sleep Res 2009;18:436-446.

51 Berry DT, Webb WB: Sleep and cognitive functions in normal older adults. J Gerontol 1985;40:331-335.

52 Hayward LB, Mant A, Eyland EA, Hewitt H, Pond CD, Saunders NA: Neuropsychological functioning and sleep patterns in the elderly. Med J Aust 1992;157:51-52.

53 Foley DJ, Masaki K, White L, Larkin EK, Monjan A, Redline S: Sleep-disordered breathing and cognitive impairment in elderly Japanese-American men. Sleep 2003;26: 596-599.

54 Ohayon MM, Vecchierini MF: Normative sleep data, cognitive function and daily living activities in older adults in the community. Sleep 2005;28:981-989.

55 Blackwell T, Yaffe K, Ancoli-Israel S, Schneider JL, Cauley JA, Hillier TA, Fink HA, Stone KL; Study of Osteoporotic Fractures Group: Poor sleep is associated with impaired cognitive function in older women: the study of osteoporotic fractures. J Gerontol A Biol Sci Med Sci 2006;61:405-410.

56 Schmutte T, Harris S, Levin R, Zweig R, Katz $\mathrm{M}$, Lipton R: The relation between cognitive functioning and self-reported sleep complaints in nondemented older adults: results from the Bronx aging study. Behav Sleep Med 2007;5:39-56

57 Nebes RD, Buysse DJ, Halligan EM, Houck PR, Monk TH: Self-reported sleep quality predicts poor cognitive performance in healthy older adults. J Gerontol B Psychol Sci Soc Sci 2009;64:180-187.

58 Faubel R, López-García E, Guallar-Castillón $\mathrm{P}$, Graciani A, Banegas JR, Rodríguez-Artalejo F: Usual sleep duration and cognitive function in older adults in Spain. J Sleep Res 2009; 18:427-435.

59 Loerbroks A, Debling D, Amelang M, Stürmer T: Nocturnal sleep duration and cognitive impairment in a population-based study of older adults. Int J Geriatr Psychiatry 2010;25: 100-109.

60 Kim SJ, Lee JH, Lee DY, Jhoo JH, Woo JI: Neurocognitive dysfunction associated with sleep quality and sleep apnea in patients with mild cognitive impairment. Am J Geriatr Psychiatry 2011;19:374-381.

61 Ferrie JE, Shipley MJ, Akbaraly TN, Marmot MG, Kivimäki M, Singh-Manoux A: Change in sleep duration and cognitive function: findings from the Whitehall II study. Sleep 2011; 34:565-573.

62 Saint Martin M, Sforza E, Barthélémy JC, Thomas-Anterion C, Roche F: Does subjective sleep affect cognitive function in healthy elderly subjects? The proof cohort. Sleep Med 2012;13:1146-1152.

63 Potvin O, Lorrain D, Forget H, Dubé M, Grenier S, Préville M, Hudon C: Sleep quality and 1 -year incident cognitive impairment in community-dwelling older adults. Sleep 2012;35: 491-499.

64 Keage HA, Banks S, Yang KL, Morgan K, Brayne C, Matthews FE: What sleep characteristics predict cognitive decline in the elderly? Sleep Med 2012;13:886-892.

65 Miyata S, Noda A, Iwamoto K, Kawano N, Okuda M, Ozaki N: Poor sleep quality impairs cognitive performance in older adults. J Sleep Res 2013;22:535-541.

66 Auyeung TW, Lee JS, Leung J, Kwok T, Leung PC, Woo J, Wing YK: Cognitive deficit is associated with phase advance of sleep-wake rhythm, daily napping, and prolonged sleep duration - a cross-sectional study in 2,947 community-dwelling older adults. Age (Dordr) 2013;35:479-486.

67 Ramos AR, Dong C, Elkind MS, Boden-Albala B, Sacco RL, Rundek T, Wright CB: Association between sleep duration and the minimental score: the Northern Manhattan study. J Clin Sleep Med 2013;9:669-673.

68 Virta JJ, Heikkilä K, Perola M, Koskenvuo M, Räihä I, Rinne JO, Kaprio J: Midlife sleep characteristics associated with late life cognitive function. Sleep 2013;36:1533-1541, $1541 \mathrm{~A}$

69 Benito-León J, Louis ED, Bermejo-Pareja F: Cognitive decline in short and long sleepers: a prospective population-based study (NEDICES). J Psychiatr Res 2013;47:19982003.

70 Lambiase MJ, Gabriel KP, Kuller LH, Matthews KA: Sleep and executive function in older women: the moderating effect of physical activity. J Gerontol A Biol Sci Med Sci 2014;69:1170-1176.

71 Lo JC, Loh KK, Zheng H, Sim SK, Chee MW: Sleep duration and age-related changes in brain structure and cognitive performance. Sleep 2014;37:1171-1178.

72 Wilckens KA, Woo SG, Kirk AR, Erickson KI, Wheeler ME: Role of sleep continuity and total sleep time in executive function across the adult lifespan. Psychol Aging 2014;29:658665

73 Devore EE, Grodstein F, Duffy JF, Stampfer MJ, Czeisler CA, Schernhammer ES: Sleep duration in midlife and later life in relation to cognition. J Am Geriatr Soc 2014;62:10731081. 
74 Gildner TE, Liebert MA, Kowal P, Chatterji S, Snodgrass JJ: Associations between sleep duration, sleep quality, and cognitive test performance among older adults from six middle income countries: results from the study on global ageing and adult health (SAGE). J Clin Sleep Med 2014;10:613-621.

75 Blackwell T, Yaffe K, Laffan A, Ancoli-Israel S, Redline S, Ensrud KE, Song Y, Stone KL; Osteoporotic Fractures in Men (MrOS) Study Group: Associations of objectively and subjectively measured sleep quality with subsequent cognitive decline in older communitydwelling men: the MrOS sleep study. Sleep 2014;37:655-663.

$76 \mathrm{Xu} \mathrm{L}$, Jiang CQ, Lam TH, Zhang WS, Cherny SS, Thomas GN, Cheng KK: Sleep duration and memory in the elderly Chinese: longitudinal analysis of the Guangzhou Biobank Cohort Study. Sleep 2014;37:17371744.

77 Miller MA, Wright H, Ji C, Cappuccio FP: Cross-sectional study of sleep quantity and quality and amnestic and non-amnestic cognitive function in an ageing population: the English longitudinal study of ageing (ELSA). PLoS One 2014;9:e100991.

78 Otsuka K, Cornelissen G, Yamanaka T, Oinuma S, Sasaki J, Yamanaka G, Okumiya K, Mat- subayashi K: Comprehensive geriatric assessment reveals sleep disturbances in community-dwelling elderly adults associated with even slight cognitive decline. J Am Geriatr Soc 2014;62:571-573.

79 Seelye A, Mattek N, Howieson D, Riley T, Wild K, Kaye J: The impact of sleep on neuropsychological performance in cognitively intact older adults using a novel in-home sensor-based sleep assessment approach. Clin Neuropsychol 2015;29:53-66.

80 Luik AI, Zuurbier LA, Hofman A, Van Someren EJ, Ikram MA, Tiemeier H: Associations of the 24-h activity rhythm and sleep with cognition: a population-based study of middle-aged and elderly persons. Sleep Med 2015; 16:850-855.

81 Van Den Berg JF, Van Rooij FJ, Vos H, Tulen JH, Hofman A, Miedema HM, Neven AK, Tiemeier H: Disagreement between subjective and actigraphic measures of sleep duration in a population-based study of elderly persons. J Sleep Res 2008;17:295-302.

82 Blackwell T, Yaffe K, Ancoli-Israel S, Redline S, Ensrud KE, Stefanick ML, Laffan A, Stone KL; Osteoporotic Fractures in Men Study Group: Associations between sleep architecture and sleep-disordered breathing and cognition in older community-dwelling men: the osteoporotic fractures in men sleep study. J Am Geriatr Soc 2011;59:22172225.

83 Kyriacou CP, Hastings MH: Circadian clocks: genes, sleep, and cognition. Trends Cogn Sci 2010;14:259-267.

84 Kondratova AA, Kondratov RV: The circadian clock and pathology of the ageing brain. Nat Rev Neurosci 2012;13:325-335.

85 Naismith SL, Hickie IB, Terpening Z, Rajaratnam SM, Hodges JR, Bolitho S, Rogers NL, Lewis SJ: Circadian misalignment and sleep disruption in mild cognitive impairment. J Alzheimers Dis 2014;38:857-866.

86 Lim AS, Kowgier M, Yu L, Buchman AS, Bennett DA: Sleep fragmentation and the risk of incident Alzheimer's disease and cognitive decline in older persons. Sleep 2013;36:10271032.

87 Tabuchi M, Lone SR, Liu S, Liu Q, Zhang J, Spira AP, Wu MN: Sleep interacts with a $\beta$ to modulate intrinsic neuronal excitability. Curr Biol 2015;25:702-712.

88 Landry GJ, Liu-Ambrose T: Buying time: a rationale for examining the use of circadian rhythm and sleep interventions to delay progression of mild cognitive impairment to $\mathrm{Al}-$ zheimer's disease. Front Aging Neurosci 2014;6:325. 